\title{
Upper cervical intramedullary spinal metastasis of ovarian carcinoma: a case report and review of the literature
}

\author{
Amrendra S Miranpuri ${ }^{1}$, Sharad Rajpal ${ }^{1}$, M Shahriar Salamat ${ }^{2}$ and John S Kuo ${ }^{1 *}$
}

\begin{abstract}
Introduction: Currently there is no generalized approach to treating patients with intra-medullary spinal metastasis. High cervical spinal cord lesions can be particularly challenging cases, and may even be considered inoperable by some.

Case report: We present what is, to the best of our knowledge, the first reported case of ovarian carcinoma (managed primarily with surgery) in a 65-year-old Caucasian woman metastasizing to the upper cervical spinal cord; we also review the relevant literature and discuss management strategies.

Conclusions: Due to improving systemic cancer therapies, patients with cancer now often survive longer and are more likely to develop central nervous system metastases. Therefore, neurosurgical oncologists are often challenged with difficult decisions about how to surgically manage these patients. We recommend individualized multidisciplinary management based on patient functional status, the need for definitive diagnosis for possible additional adjuvant therapies, and consideration of extent of systemic disease impacting on desirable quality and length of survival.
\end{abstract}

\section{Introduction}

Whereas lung and breast cancer represent the most frequently occurring spinal intra-medullary metastatic neoplasms, other solid tumors such as ovarian carcinoma can also rarely metastasize to the spinal cord. On imaging studies, the differential diagnoses for intra-medullary spinal lesions can include gliomas and vascular malformations but rare spinal infections such as tuberculosis can still be seen in some parts of the world [1,2]. The clinical presentation can range from minor neurological symptoms to major symptoms that significantly alter a patient's daily activities.

Surgical resection of intramedullary spinal metastases can be associated with significant morbidity. Management must therefore be individualized based on patient functional status, need for definitive diagnosis to guide additional therapies, and extent of systemic disease impacting on quality and length of survival. Previous

\footnotetext{
* Correspondence: j.kuo@neurosurgery.wisc.edu

'Department of Neurological Surgery, School of Medicine and Public Health, University of Wisconsin, Madison, WI, USA

Full list of author information is available at the end of the article
}

reports have described management strategies for ovarian metastases to the spinal cord. However, we describe the first ever report of a high cervical ovarian metastasis managed primarily with surgery. Such an operation has potential airway and brainstem complications. As patients with cancer are surviving their primary disease longer, neurosurgical oncologists may be faced with the challenge of treating what were traditionally believed to be inoperable lesions. A careful discussion with the patient and their family, combined with multidisciplinary input from colleagues from medical and radiation oncology are important.

\section{Case presentation}

A 65-year-old Caucasian woman underwent surgery for papillary serous ovarian adenocarcinoma involving both ovaries and with extensive metastases (stage IIIC). An exploratory laparotomy with total abdominal hysterectomy, bilateral salpingo-oophorectomy, and omentectomy with cancer staging was performed. She also underwent chemotherapy including carboplatin, paclitaxel, and cisplatin. Her CA-125 level was normal and there was no
C Biomed Central

() 2011 Miranpuri et al; licensee BioMed Central Ltd. This is an Open Access article distributed under the terms of the Creative Commons Attribution License (http://creativecommons.org/licenses/by/2.0), which permits unrestricted use, distribution, and reproduction in any medium, provided the original work is properly cited. 
evidence of disease progression at her last clinic visit at our center. Then, two years later, she re-presented with progressive neurological symptoms starting initially with limb dysesthesias and numbness and progressing to quadriparesis with urinary retention.

Imaging studies of her spine revealed an enhancing heterogeneous C2-C5 intramedullary lesion with cord expansion and edema extending rostrally into the medulla and caudally to the thoracic spinal cord (Figure 1a). Serum CA-125 was normal at presentation and a computed tomography (CT) scan of the chest, abdomen, and pelvis were negative for other lesions. An investigation for possible sources of infection was negative.

Informed consent was obtained from our patient for open surgical biopsy and possible debulking. C2-C5 laminectomies were performed for planned ultrasoundguided dorsal midline biopsy and debulking of the intramedullary mass. The tumor was debulked and the remnants of the tumor capsule dissected along the rostral and caudal margins with care taken not to injure the surrounding spinal cord. Somatosensory and motor evoked potentials did not change during surgery. A post-operative MRI scan showed the expected near total resection and expected post-laminectomy changes without any associated hematoma (Figure 1b,c). Pathologic analysis revealed histological and cytological features consistent with papillary serous ovarian adenocarcinoma (Figure 2), similar to the pathological specimen from her prior surgery. She made functional improvements after surgery and was transferred to the rehabilitation service. She gained the ability to stand with assistance using a walker, had antigravity strength in her lower extremities and 4/5 strength in her upper extremities. Fractionated radiotherapy was initiated immediately in the post-operative period during her rehabilitation.
Our patient had improvement in strength post-operatively but required an emergency re-operation three weeks later due to sudden paraplegia secondary to spinal epidural hematoma, after therapy with prophylactic subcutaneous heparin administration. On discharge a week after epidural hematoma evacuation, she experienced numbness below the umbilicus and slightly improved to left toe movement. Unfortunately, our patient died five months after discovery of her spinal metastasis, presumably from a pulmonary embolism.

\section{Discussion}

Review of the English language literature via PubMed database searches revealed five previous case reports of spinal cord ovarian cancer metastases, of which only three were tissue confirmed. Data from our report and the literature are summarized in Table 1.

Our patient's case is only the third reported tissueproven case of ovarian carcinoma metastasizing to the spinal cord and the first reported case of metastasis to the high cervical spinal cord. Historically, there has been a role for surgery in resecting a solitary metastatic lesion to the spinal cord. The limitations to surgical resection are guided by the risk of morbidity to the patient, especially with regards to neurological function. Sundaresan et al. [3] retrospectively reviewed 80 patients with solitary spinal metastasis from all cancer histologies. Overall median survival in that series following surgery was 30 months. Survival was superior in the group with breast and kidney cancers. Morbidity and recurrence, however, were higher in patients receiving prior radiation therapy. Indications for surgery include pathological diagnosis, restoration of neurological function via decompression of mass effect and spinal stabilization [3].

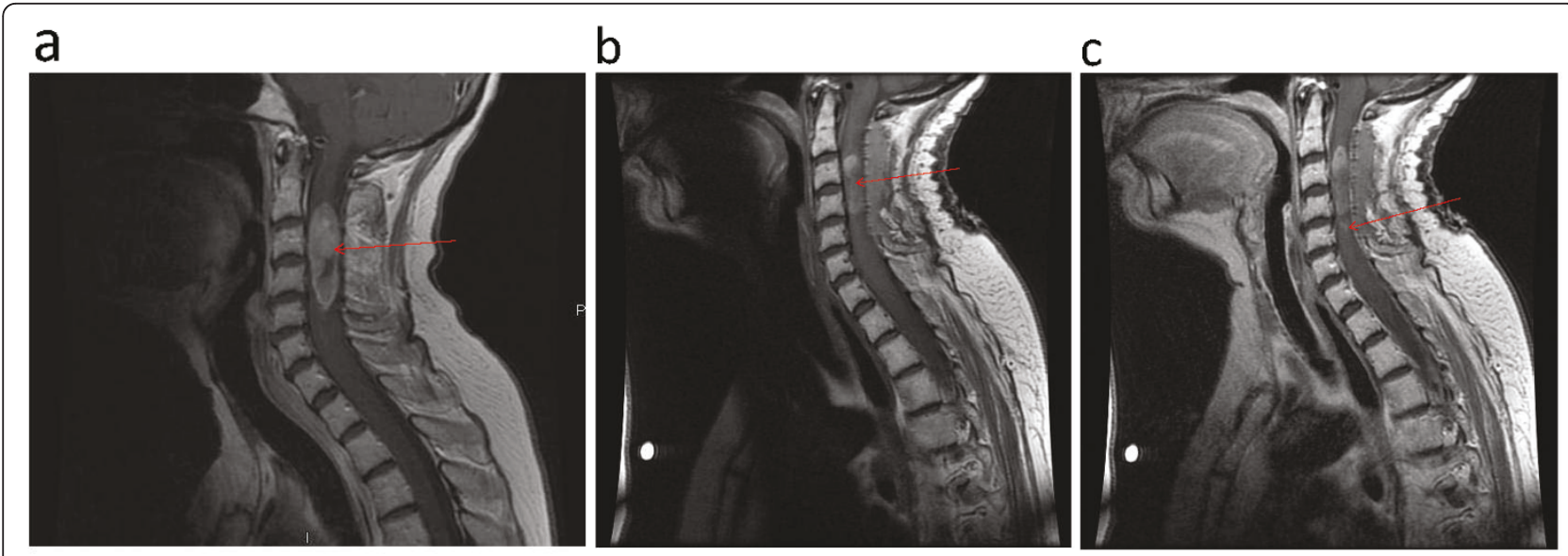

Figure 1 Sagittal cervical spine MRI. (a) Pre-surgical resection, T1 post-contrast demonstrating a $1.3 \times 4.4 \mathrm{~cm}$ intramedullary enhancing mass (left panel). (b) Post-surgical resection, T1 pre-contrast (middle panel). (c) Post-surgical resection, T1 post-contrast showing small amount of residual tumor at caudal margin of tumor (right panel). 


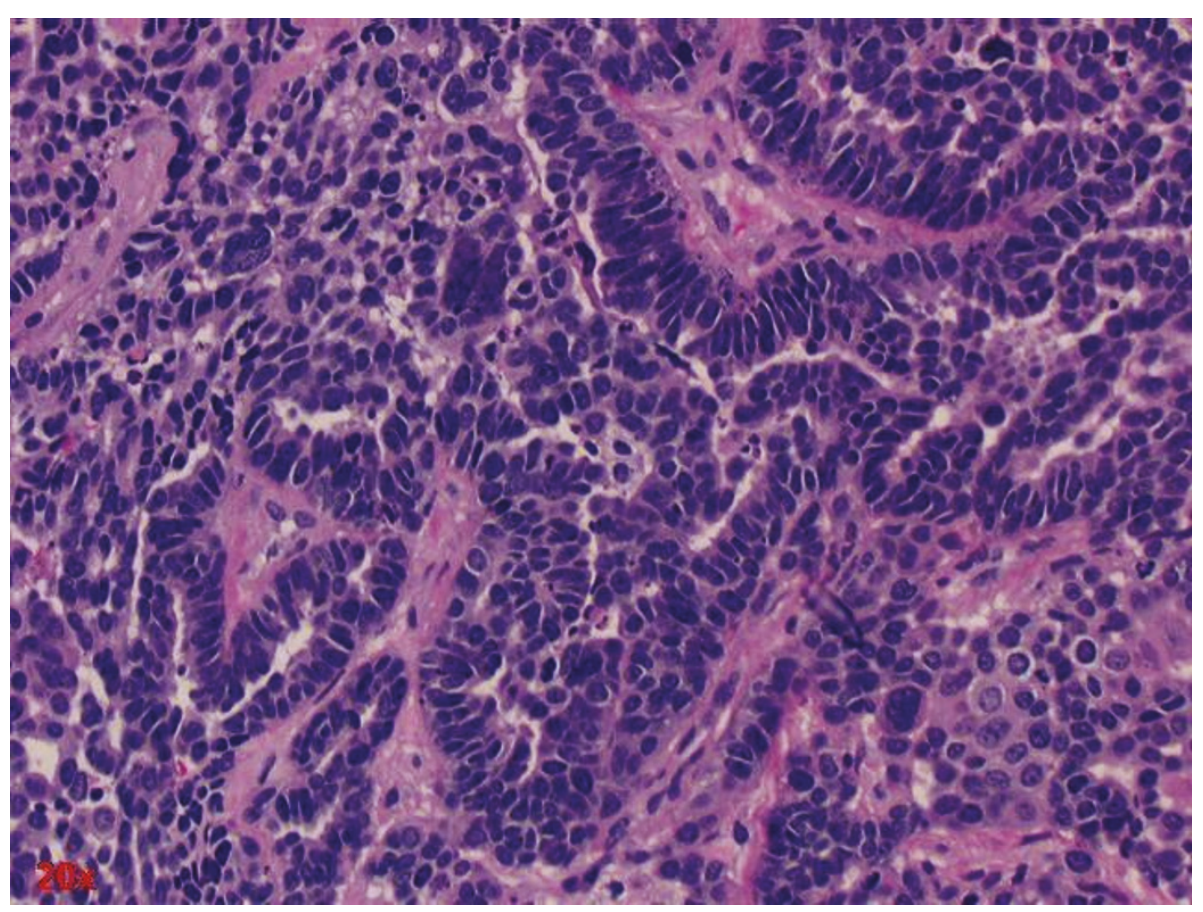

Figure 2 Hematoxylin and eosin stained section of cervical intramedullary tumor. This metastatic neoplasm was compared with prior hysterectomy and salpingo-oophorectomy of our patient and reveals similar histologic and cytologic features to the ovarian papillary serous adenocarcinoma.

The degree of tumor resection must be individualized. Rastelli et al. [4] reported gross total resection in a T11 metastatic ovarian cancer. This patient had near-complete strength improvement and MRI showed no spinal recurrence 16 months later. Even in the two cases of subtotal resection reviewed, tissue diagnosis is achieved while also achieving a less morbid operation as deemed appropriate by the involved surgeon. Isoyo et al. [5] performed a subtotal resection of a T10 metastatic ovarian lesion. This patient had no improvement in neurological status but remained alive two years after surgery.

Steroids are beneficial because it provides symptomatic relief and reduces peri-tumoral edema with a low side effect profile. The other case reports reviewed also described a 30Gy radiation dose as a preferred prescription for ovarian cancer spinal cord metastases. In select cases, simultaneous steroids and radiotherapy administration without a tissue diagnosis can be considered for

Table 1 Summary of case reports published for intramedullary ovarian spinal tumors

\begin{tabular}{|c|c|c|c|c|c|}
\hline Reference & $\begin{array}{l}\text { Lesion level } \\
\text { (enhancing } \\
\text { portion) }\end{array}$ & $\begin{array}{l}\text { Time from primary } \\
\text { diagnosis to spinal } \\
\text { metastasis diagnosis* }\end{array}$ & $\begin{array}{l}\text { Surgical } \\
\text { intervention }\end{array}$ & Adjuvant therapy & Outcome \\
\hline $\begin{array}{l}\text { Current } \\
\text { report }\end{array}$ & $\mathrm{C} 2-\mathrm{C} 5$ & two years & $\begin{array}{l}\text { Subtotal } \\
\text { resection }\end{array}$ & 30Gy and steroids & $\begin{array}{l}\text { Strength improved; three weeks post- } \\
\text { operative spinal epidural hematoma; died } \\
\text { five months later }\end{array}$ \\
\hline $\begin{array}{l}\text { Thomas et } \\
\text { al. [6] }\end{array}$ & C6-T1 & Four and a half years & None & 30Gy and steroids & Strength improved; died six months later \\
\hline $\begin{array}{l}\text { Cormio et } \\
\text { al. [8] }\end{array}$ & C5-C6 & One and a half years & None & $\begin{array}{l}\text { Steroids, chemotherapy, } \\
\text { 30Gy }\end{array}$ & Strength improved; died 10 months later \\
\hline $\begin{array}{l}\text { Isoya et al. } \\
\text { [5] }\end{array}$ & $\mathrm{T} 10$ & four years & $\begin{array}{l}\text { Subtotal } \\
\text { resection }\end{array}$ & $\begin{array}{l}\text { Radiotherapy (dose not } \\
\text { given) }\end{array}$ & $\begin{array}{l}\text { No neurological improvement; alive two } \\
\text { years after surgery }\end{array}$ \\
\hline $\begin{array}{l}\text { Rastelli et } \\
\text { al. [4] }\end{array}$ & $\mathrm{T} 11$ & two years & $\begin{array}{l}\text { Gross total } \\
\text { resection }\end{array}$ & 30Gy (10 fractions) & $\begin{array}{l}\text { Near-complete strength improvement; MRI } \\
\text { shows no spinal recurrence } 16 \text { months on }\end{array}$ \\
\hline $\begin{array}{l}\text { Bakshi et } \\
\text { al. [7] }\end{array}$ & $\begin{array}{l}\text { Conus } \\
\text { medullaris and } \\
\text { cauda equina }\end{array}$ & two years & None & $\begin{array}{l}\text { Steroids, radiotherapy } \\
\text { (dose not given), } \\
\text { chemotherapy }\end{array}$ & $\begin{array}{l}\text { Symptomatic improvement; three-year } \\
\text { complete remission }\end{array}$ \\
\hline
\end{tabular}

*Approximate time in some cases based on estimates provided in reference. 
patients at high surgical risk with poor Karnovsky scores [6,7]. Cormio et al. [8] demonstrated complete resolution of neurological symptoms with early steroids and carboplatin. Prior to the fourth cycle of carboplatin, an MRI scan of the brain showed diffuse metastatic disease for which the patient received 30Gy radiotherapy to the brain and cervical spine. In the above case report, however, no tissue diagnosis confirmation was obtained. The MRI scan performed after radiotherapy demonstrated almost complete resolution of the cervical lesion. Thus, steroids combined with chemotherapy and radiotherapy can be a viable empiric, alternative treatment regimen in high-risk surgical patients. Symptomatic and imaging responses in such cases, however, do not establish the diagnosis of ovarian spinal metastasis.

\section{Conclusions}

There is no current consensus on management of patients presenting with neurological symptoms and a potential diagnosis of spinal intramedullary metastasis. In cases of central nervous system spinal cord metastases in patients experiencing progressive neurological symptoms whose medical condition permit surgery, we advocate open surgical biopsy with resection to confirm tissue diagnosis, to reduce tumor burden for adjuvant therapies while minimizing surgical morbidity, and to accurately diagnose and treat non-metastatic diseases that may masquerade as intramedullary spinal metastases. The risks and benefits of such interventions, however, must be carefully weighed in discussions with individual patients and their families. As patients with cancer are surviving their primary disease longer, it will be critical for neurosurgical oncologists to work closely with radiation oncologists and medical oncologists to formulate individualized treatment plans for patients with central nervous system metastases, based on risk/ benefit analysis while also considering a patient's desire for quality of life and potential extent of survival.

\section{Consent}

Written informed consent was obtained from the patient's next-of-kin for publication of this case report and any accompanying images. A copy of the written consent is available for review by the Editor-in-Chief of this journal.

\section{Author details}

'Department of Neurological Surgery, School of Medicine and Public Health, University of Wisconsin, Madison, WI, USA. 'Department of Pathology and Laboratory Medicine, School of Medicine and Public Health, University of Wisconsin, Madison, WI, USA.

\section{Authors' contributions}

ASM, SR and JSK analyzed and interpreted our patient data regarding the clinical course, surgery and outcome. MSS performed the histological examination of the tumor. ASM was a major contributor in writing the manuscript. All authors read and approved the final manuscript.

\section{Competing interests}

The authors declare that they have no competing interests.

Received: 11 August 2010 Accepted: 14 July 2011

Published: 14 July 2011

\section{References}

1. Waldron JS, Cha S: Radiographic features of intramedullary spinal cord tumors. Neurosurg Clin N Am 2006, 17:13-19.

2. Ramdurg SR, Gupta DK, Suri A, Sharma BS, Mahapatra AK: Spinal intramedullary tuberculosis: a series of 15 cases. Clin Neurol Neurosurg 2009, 111:115-118

3. Sundaresan N, Rothman A, Manhart K, Kelliher K: Surgery for solitary metastases of the spine: rationale and results of treatment. Spine 2002, 27:1802-1806.

4. Rastelli F, Benedetti G, Di Tommaso L, Mazzoli M, Calbucci F, Crinò L: Intramedullary spinal metastasis from ovarian cancer. Lancet Oncol 2005, 6:123-125.

5. Isoya E, Saruhash Y, Katsuura A, Takahashi S, Matsusue Y, Hukuda S: Intramedullary spinal cord metastasis of ovarian tumor. Spinal Cord 2004, 42:485-487.

6. Thomas AW, Simon SR, Evans C: Intramedullary spinal cord metastases from epithelial ovarian carcinoma. Gynecol Oncol 1992, 44:195-197.

7. Bakshi A, Biswas G, Deshmukh C, Prasad N, Nair R, Parikh PM: Successful complete regression of isolated intramedullary spinal cord metastases from epithelial ovarian carcinoma with chemotherapy and radiotherapy. Indian J Cancer 2006, 43:136-138.

8. Cormio G, Di Vagno G, Di Fazio F, Loverro G, Selvaggi L: Intramedullary spinal cord metastasis from ovarian carcinoma. Gynecol Oncol 2001, 81:506-508.

doi:10.1186/1752-1947-5-311

Cite this article as: Miranpuri et al:: Upper cervical intramedullary spinal metastasis of ovarian carcinoma: a case report and review of the literature. Journal of Medical Case Reports 2011 5:311.

\section{Submit your next manuscript to BioMed Central and take full advantage of:}

- Convenient online submission

- Thorough peer review

- No space constraints or color figure charges

- Immediate publication on acceptance

- Inclusion in PubMed, CAS, Scopus and Google Scholar

- Research which is freely available for redistribution
C Biomed Central 